\title{
MODEL KEPUTUSAN BERKUNJUNG PADA OBYEK WISATA DI KOTA SEMARANG
}

\author{
DC. Kuswardani', Tri Endang Yani2 \\ Fakultas Ekonomi, Universitas Semarang \\ Jalan Arteri Soekarno Hatta Tlogosari, Semarang - Jawa Tengah \\ Email Korespondensi:dhani_dc@yahoo.co.id
}

\begin{abstract}
ABSTRAK
Tujuan penelitian ini memberikan kontribusi untuk mengoptimalkan pariwisata di kota Semarang. Variabel yang diuji untuk mengoptimalkan keputusan mengunjungi obyek wisata di kota Semarang secara langsung adalah Gaya Hidup, Destinasi Image, Atribut Produk Wisata dan Electronic Word of Mouth merupakan variabel yang diduga memoderatori pengaruh Gaya Hidup pada Keputusan berkunjung pada obyek wisata di kota Semarang. Populasi adalah semua pengunjung obyek wisata di kota Semarang, sedangkan sampel ditentukan sebesar 100 responden dengan menggunakan teknik Cluster Sampling. Alat analisis yang dipergunakan adalah Structural Equation Medelling (SEM) dengan aplikasi program Partial Least Square (PLS) yaitu smartPLS. ${ }^{3.0}$ Hasil pengujian hipotesis menunjukkan bahwa semua Hipotesis didukung. Gaya Hidup, Destination Image dan Atribut Produk Wisata positif signifikan berpengaruh pada Keputusan berkunjung pada obyek wisata di kota Semarang. Electronic Word of Mouth terbukti berperan sebagai Pure Moderator dalam memoderasi pengaruh Gaya Hidup pada Keputusan berkunjung pada obyek wisata di kota Semarang.
\end{abstract}

Kata Kunci: Gaya Hidup, Destinasi Image dan Atribut Produk Wisata, Electronic Word of Mouth, Keputusan berkunjung pada obyek wisata di kota Semarang

\begin{abstract}
The purpose of this study is to contribute to optimizing tourism in the city of Semarang. The variables tested to optimize the decision to visit attractions in the city of Semarang directly are Lifestyle, Destination Image and Tourism Product Attributes. Electronic Word of Mouth is a variable that moderates the influence of Lifestyle on the decision to visit tourist attractions in the city of Semarang. The population is all tourist attractions in the city of Semarang, while the sample is determined by 100 respondents using the Cluster Sampling technique. The analytical tool used is Structural Equation Modelling (SEM) with Partial Least Square (PLS) application program, namely smartPLS.3.0 The results of hypothesis testing indicate that all hypotheses are supported. Lifestyle, Destination Image and Attributes of Tourism Products have a significant positive effect on the decision to visit tourist attractions in the city of Semarang. Electronic Word of Mouth is proven to play a role as Pure Moderator in moderating the influence of Lifestyle on the decision to visit tourist attractions in the city of Semarang.
\end{abstract}

Keywords: Lifestyle, Destination Image and Tourism Product Attributes, Electronic Word of Mouth, the decision to visit attractions in the city of Semarang 


\section{PENDAHULUAN}

Salah satu sektor pendorong pertumbuhan ekonomi suatu negara adalah sektor pariwisata. Indonesia sebagai negara berkembang yang memiliki wilayah dengan potensi daya tarik wisata menjadikan pariwisata sebagai penunjang perekonomian yang memiliki prospek cerah. Pertumbuhan ekonomi dapat ditingkatkan antara lain melalui pariwisata yang dikembangkan dengan optimal, karena kegiatan pariwisata mampu menciptakan lapangan pekerjaan, mensejahterakan masyarakat dan pendapatan daerah.

Kota Semarang yang berada di pantai utara Jawa Tengah dengan dibatasi kabupaten Kendal disebelah barat, disebelah timur Kabupaten Demak, kabupaten Semarang disebelah selatan dan laut jawa disebelah utara, merupakan kota transit regional Jawa Tengah. Posisi penting ditingkat nasional dari segi ekonomi, politik, budaya, dan keamanan serta sebagai kota strategis di pesisir utara kota Jawa menjadikan kota Semarang menjadi kota perdagangan dan sekaligus sebagai tujuan wisata dengan berbagai tawaran obyek wisata.

Pertumbuhan ekonomi dapat ditingkatkan antara lain melalui pariwisata yang dikembangkan dengan optimal. Kegiatan pariwisata mampu menciptakan lapangan pekerjaan, mensejahterakan masyarakat dan pendapatan daerah. Kota Semarang sebagai kota transit diharapkan mampu menjadi tujuan wisata. Kenyataannya pada th 2018 terjadi penurunan jumlah wisatawan ke Kota Semarang mencapai 13,37 persen, hal tersebut dikatakan oleh Sinoeng Rachmadi sebagai Kepala Dinas Pemuda, Olahraga dan Pariwisata Jateng. Tahun 2019 (sampai bulan Juni) target pencapaian jumlah wisatawan belum terpenuhi, hal tersebut dapat diketahui dari instruksi Walikota Semarang kepada Kepala Dinas Pemuda, Olahraga dan Pariwisata Jateng agar capaian target wisatawan di kota Semarang sebanyak 7,2 juta wisatawan, sementara sampai akhir bulan Juni baru mencapai 3,7 juta wisatawan $(48,11 \%)$.

Secara umum dalam mempelajari perilaku konsumen dapat dilakukan melalui Life Style (Gaya Hidup), Kavak dan Gumusluoglu (2007) menemukan bahwa gaya hidup menjadi alasan individu dalam mengambil keputusan membeli berkaitan dengan pilihan merk di ibu kota Ankara, Turki, yang mengakui 13 lingkup gaya hidup. Menurut Kim et. al., (2003) gaya hidup, berpengaruh pada keputusan konsumen pada jenis penginapan yang lebih mereka sukai. Life style (gaya hidup) menjadi variabel yang kontradiksi terkait keputusan pembelian berkunjung ke obyek wisata di kota Semarang. Penelitian Anita, (2016) menyimpulkan bahwa konsumen wanita India lebih sadar terhadap faktor gaya hidup. Herawan dan Supriono, (2018) menunjukkan bahwa Gaya hidup menjadi faktor konsumen memutuskan berkunjung ke obyek wisata. Sementara penelitian Mohiudin, (2018) menemukan bahwa Gaya Hidup wanita Pakistan tidak berpengaruh pada keputusan membeli. Electronic word of mouth diindikasikan dapat menutup kesenjangan life style (gaya hidup) pada keputusan berkunjung ke obyek wisata di kota Semarang. Atribut produk merupakan alat yang dapat mendukung dan melengkapi manfaat utama dari produk atau jasa yang ditawarkan, dan dianggap penting serta dijadikan dasar dalam pengambilan keputusan pembelian, dan atribut produk wisata serta destination image diharapkan mampu meningkatkan keputusan berkunjung ke obyek wisata di kota Semarang.

\section{Perumusan Masalah}

Kota Semarang sebagai kota transit diharapkan mampu menjadi tujuan wisata, dengan jumlah pengunjung obyek wisata yang tinggi. Perumusan masalah pada 
penelitian ini adalah bagaimana mewujudkan kota Semarang menjadi kota tujuan wisata melalui identifikasi faktor yang menyebabkan masyarakat bersedia berkunjung pada obyek wisata di kota Semarang.

\section{Keputusan Membeli Jasa}

Hasil dari proses yang akan membawa pada pilihan suatu tindakan diantara beberapa pilihan yang tersedia disebut dengan Pengambilan Keputusan, oleh karenanya proses mengambil keputusan selalu menghasilkan satu pilihan akhir. Mardhotillah dan Saino, (2013) menunjukan bahwa keputusan pembelian adalah tahap proses pengambilan keputusan di mana konsumen membeli produk dan dapat terjadi jika konsumen menerima layanan dari penyedia layanan.

\section{Gaya Hidup}

Cara mengelompokkan konsumen secara psikografis melalui Gaya hidup. Pada prinsipnya gaya hidup merupakan cara seseorang menghabiskan waktu dan uang yang dimiliki. Perilaku seseorang dipengaruhi oleh Gaya hidup, yang pada akhirnya mampu menentukan pilihan setiap akan mengkonsumsi barang atau jasa.

Gaya Hidup menurut Zaeema, (2018) dan Qing, et.al., (2012) adalah cara hidup, yang diidentifikasi melalui aktivitas seseorang, minat, dan pendapat seseorang. Gaya hidup adalah perspektif penting ketika konsumen memutuskan membeli, yang dapat dilihat melalui tingkat usia dan pendapatannya (Pangestu dkk., 2016).

\section{Destination Image.}

Industri pariwisata memiliki sifat yang sama dengan industri jasa yang lain yaitu intangibility, inseparability, heterogeneity, dan perishability. Evaluasi ketersediaan destinasi obyek wisata menjadi terbatas karena sifat industri jasa tersebut, oleh karena keterbatasan tersebut menyebabkan wisatawan mengambil keputusan berkaitan dengan obyek wisata melalui citra obyek wisata. Obyek wisata yang dcitrakan wisatawan tidak selalu sesuai dengan kondisi nyata obyek wisata tersebut. Hal tersebut menyebabkan citra destinasi memiliki potensi dalam mempengaruhi keputusan memilih obyek wisata.

Komponen utama citra adalah fungsional dan emosional, (Coban, 2012). Citra fungsional selalu terkait dengan yang mudah dilihat dan diukur oleh wisatawan, sementara citra emosional berhubungan dengan aspek psikologis yang hanya bisa ditasakan dan disikapi pada suatu destinasi. Citra destinasi merupakan proses yang dibuat wisatawan untuk membandingkan atribut pada destinasi yang berbeda. (Asli et $a l .$, 2007).

\section{Atribut Produk Wisata}

Widya, dkk (2017) mengatakan bahwa keseluruhan layanan yang dinikmati wisatawan sampai ke obyek kunjungan wisata dan kembali ke tempat asal ketika berangkat, didefinisikan sebagai atribut produk wisata. Aspek utama produk wisata yang berdampak pada potensi wisatawan berkunjung ke obyek wisata menurut Bintang (2018), adalah daya tarik wisata melalui tawaran atraksi pada obyek wisata, kemudahan mencapai obyek wisata dan ketersediaan fasilitas pada obyek wisata.

\section{Electronic word of mouth}

Arief, (2019) mengatakan bahwa sumber informasi bersifat nonkomersial yang dapat membentuk sikap konsumen dalam berperilaku membeli adlah word of mouth. Pertumbuhan internet yang sangat cepat menyebabkan konsumen lebih mudah terlibat 
pada iklan nonkomersial dan memperbincangkan pengalamannya mengkonsumsi produk dan merek tertentu (Chevalier dan Mayzlin, 2006).

\section{METODE PENELITIAN}

\section{Jenis Penelitian}

Variabel penelitian meliputi variabel independen yaitu Gaya Hidup, Destination Image, Atribut Produk Wisata dengan Electronic Word of Mouth sebagai variabel moderating dan variabel dependen Keputusan berkunjung ke tempat wisata.

\section{Lokasi Penelitian}

Lokasi penelitian yang dipilih adalah obyek wisata di kota Semarang, yaitu lawang sewu, sampookong, kota lama, kampung pelangi, taman virgin, maerokoco, gedung songo, goa kreo, manunggal, marina, sampookong, kota lama, goa kreo, pantai marina, lawang sewu, masjid agung, brown canyon, maerokoco, lawang sewu, masjid agung, celosia dan kampung batik.

\section{Definisi Operasional Variabel dan Indikator Pengukuran}

Tabel 1. Variabel dan Indikator Variabel Penelitian

\begin{tabular}{|c|c|c|c|c|}
\hline No. & $\begin{array}{c}\text { Nama } \\
\text { Variabel }\end{array}$ & Definisi Operasional & Indikator & Sumber \\
\hline 1 & $\begin{array}{l}\text { Keputusan } \\
\text { berkunjung ke } \\
\text { tempat wisata }\end{array}$ & $\begin{array}{l}\text { keputusan } \\
\text { berkunjung adalah } \\
\text { perilaku pembelian } \\
\text { seseorang dalam } \\
\text { menentukan suatu } \\
\text { pilihan tempat wisata } \\
\text { untuk mencapai } \\
\text { kepuasan sesuai } \\
\text { kebutuhan dan } \\
\text { keinginan konsumen }\end{array}$ & $\begin{array}{l}\text { 1.Pengenalan kebutuhan } \\
\text { 2.Pencarian informasi } \\
\text { 3.Evaluasi Alternatif } \\
\text { 4. Melakukan pembelian } \\
\text { 5.Perilaku setelah } \\
\text { pembelian }\end{array}$ & $\begin{array}{l}\text { Mardhotillah } \\
\text { dan Saino, } \\
(2013)\end{array}$ \\
\hline 2 & Gaya Hidup & $\begin{array}{l}\text { gaya hidup adalah } \\
\text { kondisi yang } \\
\text { diciptakan dimana } \\
\text { orang melakukan } \\
\text { kegiatan dan } \\
\text { menggunakan uang } \\
\text { dan waktunya baik } \\
\text { dari minat atau opini } \\
\text { dari orang atau } \\
\text { karena prestise } \\
\text { (gengsi) dan status } \\
\text { sosial }\end{array}$ & $\begin{array}{ll}\text { 1. } & \text { Kegiatan } \\
\text { 2. } & \text { Minat } \\
\text { 3. } & \text { Opini }\end{array}$ & $\begin{array}{l}\text { Coban, } \\
(2012)\end{array}$ \\
\hline 3 & Destination & sejumlah gambaran, & 1. atraksi wisata & Asya,dkk, \\
\hline
\end{tabular}




\begin{tabular}{|c|c|c|c|c|}
\hline No. & $\begin{array}{c}\text { Nama } \\
\text { Variabel }\end{array}$ & Definisi Operasional & Indikator & Sumber \\
\hline & Image & $\begin{array}{l}\text { kepercayaan, } \\
\text { persepsi dan pikiran } \\
\text { dari wisatawan } \\
\text { terhadap suatu } \\
\text { destinasi yang } \\
\text { melibatkan berbagai } \\
\text { produk dan atribut } \\
\text { wisata destinasi } \\
\text { terkait. }\end{array}$ & $\begin{array}{l}\text { 2. fasilitas dasar } \\
\text { 3. atraksi budaya } \\
\text { 4. aksesibilitas } \\
\text { 5. substruktur pariwisata } \\
\text { 6. lingkungan alam }\end{array}$ & (2016) \\
\hline 4 & $\begin{array}{l}\text { Atribut } \\
\text { produk wisata }\end{array}$ & $\begin{array}{l}\text { Atribut produk } \\
\text { wisata adalah } \\
\text { keseluruhan } \\
\text { pelayanan yang } \\
\text { diperoleh dan } \\
\text { dirasakan atau } \\
\text { dinikmati wisatawan } \\
\text { yang dapat dinilai } \\
\text { dan dianggap penting } \\
\text { oleh konsumen dan } \\
\text { dijadikan dasar } \\
\text { pengambilan } \\
\text { keputusan pembelian }\end{array}$ & $\begin{array}{l}\text { 1. Daya tarik wisata } \\
\text { 2. fasilitas } \\
\text { 3. kemudahan dalam } \\
\text { mencapai tujuan } \\
\text { wisata. }\end{array}$ & $\begin{array}{l}\text { Husain dan } \\
\text { Islam, } \\
(2019)\end{array}$ \\
\hline 5 & $\begin{array}{l}\text { Electronic } \\
\text { word of mouth }\end{array}$ & $\begin{array}{l}\text { Memadukan dan } \\
\text { mengkoordinasikan } \\
\text { beberapa saluran } \\
\text { komunikasi untuk } \\
\text { menjukan pesan yang } \\
\text { jelas, konsisten, dan } \\
\text { menarik tentang } \\
\text { organisasi dan } \\
\text { produknya. }\end{array}$ & $\begin{array}{l}\text { 1. Kemauan konsumen } \\
\text { dalam membicarakan } \\
\text { hal - hal positif } \\
\text { 2. Rekomendasi pada } \\
\text { orang lain. } \\
\text { 3. Dorongan pada teman }\end{array}$ & Kiky., 2018 \\
\hline
\end{tabular}

Sumber : jurnal terkait

\section{Populasi, Sampel, dan Sumber Data}

Sampel ditentukan dengan menggunakan teknik Probability Sampling, khususnya Cluster Sampling. Jumlah sampel dalam penelitian ini ditentukan dengan menggunakan pendapat Sugiyono, (2016) bahwa ukuran sampel yang layak antara 30 sampai 500 dan apabila menggunakan analisis multivariat maka jumlah sampel minimal 10 kali jumlah variabel. Variabel pada penelitian ini terdiri dari 1 variabel dependent, 3 variabel independent dan 1 variabel moderating, oleh karenanya minimal sampel adalah 50 elemen dan penelitian ini jumlah sampel ditentukan 100 responden. Data yang digunakan dibedakan menjadi dua sumber, yaitu (1) data primer, dan (2) data sekunder. Data primer merupakan data penelitian yang diperoleh secara langsung yang diperoleh dari responden yaitu pengunjung obyek wisata di Kota Semarang. Alat untuk memperoleh data primer dengan menggunakan kuesioner berdasarkan variabel-variabel 
yang diteliti, berupa data persepsi. Data Sekunder berupa data jenis obyek wisata yang ditawarkan di kota Semarang.

\section{Model Penelitian}

Model yang digunakan pada penelitian ini seperti pada Gambar 1.

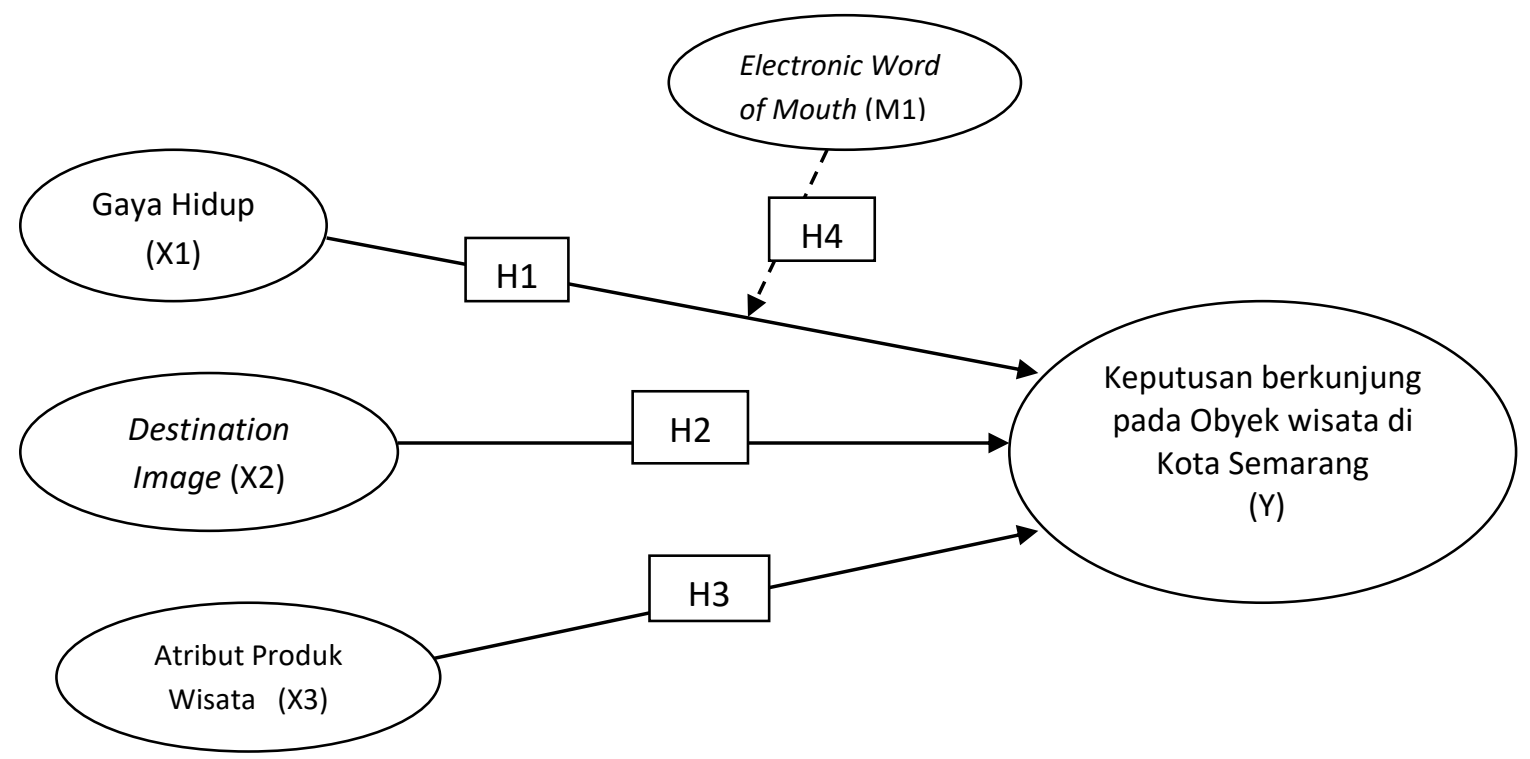

Gambar 1. Model Penelitian

Adapun Hipotesis yang dirumuskan berdasarkan model pada Gambar 1 adalah

H1 : Gaya Hidup berpengaruh langsung pada Keputusan berkunjung pada obyek wisata

H2 : Destination Image berpengaruh langsung pada Keputusan berkunjung pada obyek wisata

H3 : Atribut Produk Wisata berpengaruh langsung pada Keputusan berkunjung pada obyek wisata

H4 : Electronic Word of Mouth memoderasi pengaruh Gaya Hidup pada Keputusan berkunjung pada obyek wisata

\section{Metode Analisis}

Data yang diperoleh dari lapangan dianalisis secara kuantitatif menggunakan alat analisis smartPLS. Analisis kuantitatif digunakan untuk membuktikan adanya hubungan antar variabel. Hasil penelitian ini dapat menghasilkan model terkait dengan faktor yang menyebabkan masyarakat mau berkunjung pada obyek wisata di kota Semarang, sehingga Kota Semarang dapat menjadi kota tujuan wisata. 


\section{HASIL DAN PEMBAHASAN}

\section{Uji Validitas}

Suatu indikator dinyatakan valid jika mempunyai loading factor di atas 0,5 pada konstruk yang dituju. Tabel 2 menunjukan nilai loading factor yang menghasilkan variabel dengan indikator valid.

Tabel 2. Hasil Uji Validitas

\begin{tabular}{|c|c|c|c|c|c|}
\hline Indikator & $\mathrm{X} 1$ & $\mathrm{X} 2$ & $\mathrm{X} 3$ & M & $\mathrm{Y}$ \\
\hline $\mathrm{X} 1.2$ & 0,602211 & & & & \\
\hline $\mathrm{X} 1.3$ & 0.80873 & & & & \\
\hline $\mathrm{X} 1.4$ & 0,82342 & & & & \\
\hline X1.6 & 0,80873 & & & & \\
\hline $\mathrm{X} 1.7$ & 0,797041 & & & & \\
\hline $\mathrm{X} 1.8$ & 0,842218 & & & & \\
\hline $\mathrm{X} 1.12$ & 0,842218 & & & & \\
\hline X1.13 & 0,768017 & & & & \\
\hline $\mathrm{X} 2.2$ & & 0,710926 & & & \\
\hline $\mathrm{X} 2.3$ & & 0,803578 & & & \\
\hline $\mathrm{X} 2.4$ & & 0,69416 & & & \\
\hline $\mathrm{X} 2.10$ & & 0,759093 & & & \\
\hline $\mathrm{X} 2.11$ & & 0,701123 & & & \\
\hline $\mathrm{X} 2.12$ & & 0,778774 & & & \\
\hline $\mathrm{X} 3.1$ & & & 0,768699 & & \\
\hline $\mathrm{X} 3.2$ & & & 0,807936 & & \\
\hline $\mathrm{X} 3.3$ & & & 0,747361 & & \\
\hline X3.4 & & & 0,824989 & & \\
\hline M1.1 & & & & 0,812664 & \\
\hline M1.2 & & & & 0,850514 & \\
\hline M1.3 & & & & 0,807534 & \\
\hline M1.4 & & & & 0,765216 & \\
\hline M1.5 & & & & 0,752601 & \\
\hline Y1.2 & & & & & 0,776985 \\
\hline Y1.5 & & & & & 0,791209 \\
\hline Y1.6 & & & & & 0,820986 \\
\hline Y1.7 & & & & & 0,775735 \\
\hline Y1.8 & & & & & 0,76555 \\
\hline Y1.9 & & & & & 0,600359 \\
\hline
\end{tabular}

Sumber : data primer yang diolah, 2019

Metode lain untuk melihat discriminant validity dengan melihat nilai square root of average variance extracted (AVE). Nilai yang disarankan apabila melihat discriminant validity melalui nilai AVE harus di atas 0,5. Tabel 3. menunjukkan nilai AVE yang dihasilkan pada penelitian ini mempunyai nilai $>0,5$, yang bermakna bahwa semua konstruk pada penelitian ini dapat digunakan sebagai variabel penelitian. 
Tabel 3. Nilai Average Variance Extracted (AVE)

\begin{tabular}{|l|c|}
\hline \multicolumn{1}{|c|}{ Variabel } & $\begin{array}{c}\text { Average Variance Extracted } \\
\text { (AVE) }\end{array}$ \\
\hline X1 (Gaya Hidup) & 0,624069 \\
\hline X2 (Destination Image) & 0,551216 \\
\hline X3 (Atribut Produk Wisata) & 0,620703 \\
\hline M (Electronic Word of Mouth) & 0,637574 \\
\hline $\begin{array}{l}\text { Y (Keputusan Berkunjung ke Obyek Wisata } \\
\text { Kota Semarang) }\end{array}$ & 0,575333 \\
\hline
\end{tabular}

Sumber : data primer yang diolah, 2019

\section{Uji Reliabilitas.}

Uji Reliabilitas dilakukan dengan melihat nilai Composite Reliability, hasil composite reliability akan menunjukkan nilai yang memuaskan jika di atas 0,7 . Tabel 4 menunjukan composite reliability untuk semua konstruk di atas 0,7, yang bermakna bahwa semua konstruk pada model yang diestimasi memenuhi kriteria discriminant validity.

Tabel 4. Nilai Composite Reliability

\begin{tabular}{|l|c|}
\hline \multicolumn{1}{|c|}{ Variabel } & Composite Reliability \\
\hline X1 (Gaya Hidup) & 0,929409 \\
\hline X2 (Destination Image) & 0,880187 \\
\hline X3 (Atribut Produk Wisata) & 0,867301 \\
\hline M (Electronic Word of Mouth) & 0,897738 \\
\hline $\begin{array}{l}\text { Y (Keputusan Berkunjung ke Obyek Wisata Kota } \\
\text { Semarang) }\end{array}$ & 0,889584 \\
\hline
\end{tabular}

Sumber : data primer yang diolah, 2019

Uji reliabilitas dapat diperkuat dengan menunjukan koefisien Cronbach's Alpha, hasil koefisien Cronbach's Alpha yang disarankan di atas 0,6. Tabel 5 menunjukan Cronbach's Alpha untuk semua konstruk di atas 0,6, yang bermakna bahwa semua konstruk pada model memenuhi kriteria reliable.

Tabel 5. Nilai Cronbach's Alpha

\begin{tabular}{|l|l|}
\hline \multicolumn{1}{|c|}{ Variabel } & \multicolumn{1}{c|}{$\begin{array}{c}\text { Cronbach's } \\
\text { Alpha }\end{array}$} \\
\hline X1 (Gaya Hidup) & 0,913856 \\
\hline X2 (Destination Image) & 0,837437 \\
\hline X3 (Atribut Produk Wisata) & 0,796916 \\
\hline M (Electronic Word of Mouth) & 0,857437 \\
\hline Y (Keputusan Berkunjung ke Obyek Wisata Kota Semarang) & 0,851322 \\
\hline
\end{tabular}

Sumber : data primer yang diolah, 2019 


\section{Pengujian Hipotesis}

Hipotesis pada penelitian ini diuji dengan menggunakan metode Partial Least Square (PLS). Hipotesis diuji dengan menggunakan analisis SmartPLS BootStraping untuk mengetahui pengaruh variabel latent/variabel eksogen (variabel X) pada variabel Endogen (Y). Hasil uji hipotesis diketahui dari koefisien t statistik dan original sample estimate yaitu koefisien $\mathrm{t}$ statistik menunjukkan signifikansi konstruk dan original sample estimate menunjukkan sifat hubungan antar konstruk (positip atau negative) seperti pada Gambar 2.

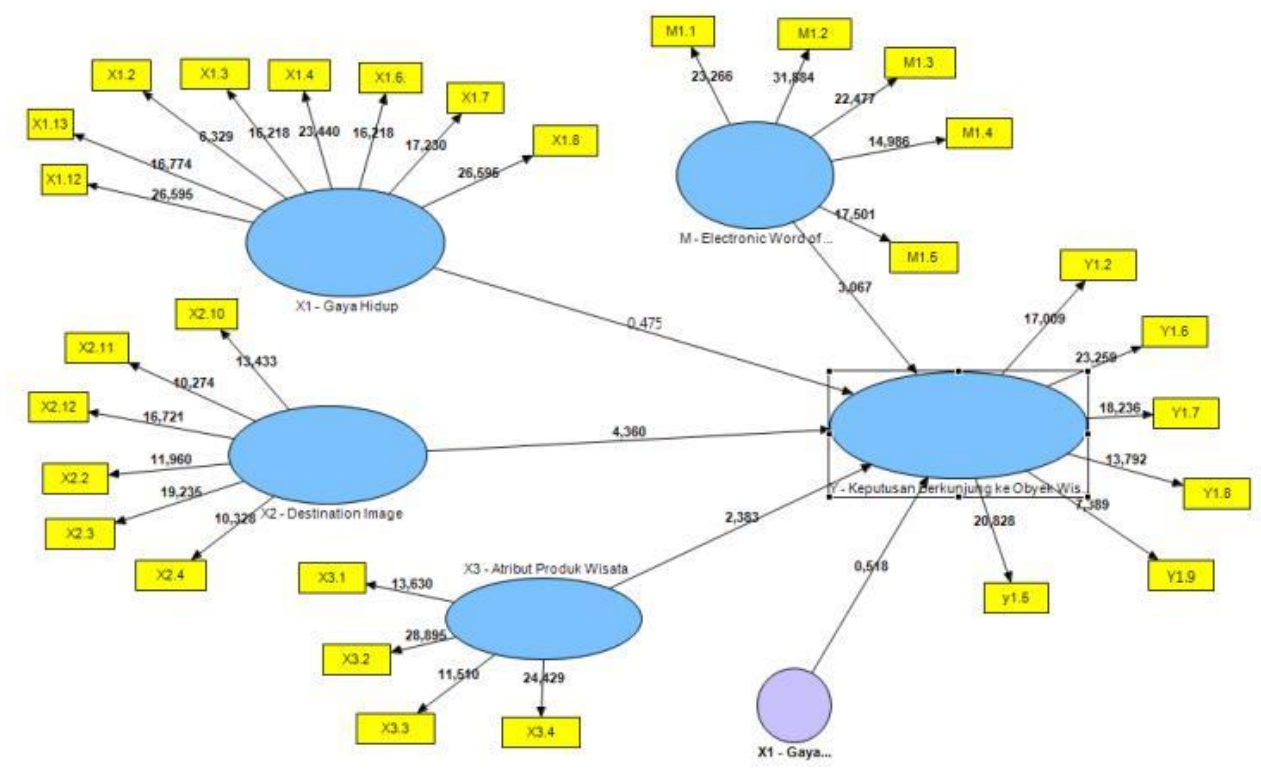

Gambar 2. Structural Model Bootstrapping

Hasil uji Hipotesis semua variabel penelitian ditunjukkan pada Tabel 6 . Hipotesis didukung apabila $t_{\text {statistik }}$ lebih besar dari $t_{\text {tabel, }}$, demikian sebaliknya apabila $\mathrm{t}_{\text {statistik }}$ lebih kecil dari $\mathrm{t}_{\text {tabel, }}$, maka hipotesis penelitian ditolak. Koefisien Original Sample menunjukkan arah pengaruh antar variabel konstruk.

Nilai $t_{\text {statistik }}$ sebesar 4,0747 (> 1,96) pada variabel Gaya Hidup seperti tersebut di Tabel 1.6. mempunyai arti bahwa Gaya Hidup terbukti signifikan pada Keputusan Berkunjung ke Obyek Wisata di Kota Semarang. Nilai original sample estimate sebesar +0,1187 memberi arti arah pengaruh Gaya Hidup pada Keputusan Berkunjung ke Obyek Wisata di Kota Semarang positif. Hal tersebut bermakna bahwa Hipotesis 1 yang menyatakan bahwa Gaya Hidup berpengaruh pada Keputusan Berkunjung ke Obyek Wisata di Kota Semarang didukung.

Nilai $t_{\text {statistik }}$ pengaruh antara Destination Image dengan Keputusan Berkunjung ke Obyek Wisata di Kota Semarang yang ditunjukan pada Tabel 1.6. sebesar 4,3603 (> 1,96), hal tersebut bermakna bahwa pengaruh antara Destination Image dengan Keputusan Berkunjung ke Obyek Wisata di Kota Semarang signifikan. Nilai original sample estimate sebesar $+0,3203$, menunjukkan bahwa arah pengaruh Destination Image pada Keputusan Berkunjung ke Obyek Wisata di Kota Semarang positif. Maknanya bahwa hipotesis 2 yang menyatakan bahwa Destination Image berpengaruh pada Keputusan Berkunjung ke Obyek Wisata di Kota Semarang didukung 
Tabel 6. Hasil Uji Hipotesis

\begin{tabular}{|l|c|c|c|}
\hline \multicolumn{1}{|c|}{ Variabel } & $\begin{array}{c}\text { Original Sample } \\
(\mathrm{O})\end{array}$ & $\begin{array}{c}\text { t Statistics } \\
(|\mathrm{O} / \mathrm{STERR}|)\end{array}$ & Hipotesis \\
\hline $\begin{array}{l}\text { M - Electronic Word of Mouth -> Y - } \\
\text { Keputusan Berkunjung ke Obyek Wisata } \\
\text { Kota Semarang }\end{array}$ & 0,77028 & 0,36759 & ditolak \\
\hline $\begin{array}{l}\text { X1 - Gaya Hidup -> Y - Keputusan } \\
\text { Berkunjung ke Obyek Wisata Kota Semarang }\end{array}$ & 0,1187 & 4,0747 & didukung \\
\hline $\begin{array}{l}\text { X1 - Gaya Hidup * M - Electronic Word of } \\
\text { Mouth -> Y - Keputusan Berkunjung ke } \\
\text { Obyek Wisata Kota Semarang }\end{array}$ & 0,2106 & 5,0178 & didukung \\
\hline $\begin{array}{l}\text { X2 - Destination Image -> Y - Keputusan } \\
\text { Berkunjung ke Obyek Wisata Kota Semarang }\end{array}$ & 0,3203 & 4,3603 & didukung \\
\hline $\begin{array}{l}\text { X3 - Atribut Produk Wisata -> Y - Keputusan } \\
\text { Berkunjung ke Obyek Wisata Kota Semarang }\end{array}$ & 0,1990 & 2,3828 & didukung \\
\hline
\end{tabular}

Sumber : data Primer yang diolah, 2019

Pada Tabel 6. menunjukkan bahwa nilai $t_{\text {statistik }}$ sebesar 2,3828 (>1,96), bermakna bahwa pengaruh Atribut Produk Wisata dengan Keputusan Berkunjung ke Obyek Wisata di Kota Semarang signifikan. Nilai original sample estimate sebesar +0,1990 menunjukkan bahwa arah pengaruh antara Atribut Produk Wisata dengan Keputusan Berkunjung ke Obyek Wisata di Kota Semarang positif. Artinya Hipotesis 3 yang menyatakan bahwa Atribut Produk Wisata berpengaruh pada Keputusan Berkunjung ke Obyek Wisata di Kota Semarang didukung.

Hasil uji moderasi ditunjukan pada Tabel 6 bahwa interaksi variabel Electronic Word of Mouth dengan variabel Gaya Hidup $\left(\mathrm{M}^{*} \mathrm{X} 1\right)$ pada variabel Keputusan Berkunjung ke Obyek Wisata di Kota Semarang sebesar 5,0178 lebih besar dari tabel

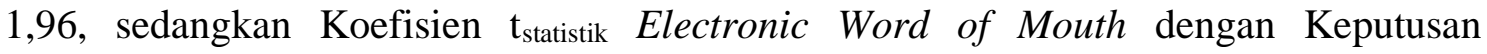
Berkunjung ke Obyek Wisata di Kota Semarang sebesar 0,36759 lebih kecil dari tabel 1,96, artinya pengaruh Electronic Word of Mouth pada Keputusan Berkunjung ke Obyek Wisata di Kota Semarang tidak signifikan. Hal tersebut bermakna bahwa Electronic Word of Mouth mampu berperan sebagai pure moderator. Nilai original sample estimate sebesar +0,2106 menunjukkan bahwa arah Electronic Word of Mouth memoderasi pengaruh Gaya Hidup pada Keputusan Berkunjung ke Obyek Wisata di Kota Semarang positip. Hal tersebut bermakna bahwa Hipotesis 4 yang menyatakan bahwa Electronic Word of Mouth memoderasi pengaruh Gaya Hidup pada Keputusan Berkunjung ke Obyek Wisata di Kota Semarang didukung.

Nilai tertinggi original sample estimate yang ditunjukkan Tabel 5.7. sebesar +0,3203 pada Destination Image. Hal tersebut mempunyai arti bahwa Destination Image mempunyai pengaruh pada Keputusan Berkunjung ke Obyek Wisata di Kota Semarang lebih tinggi dibandingkan Atribut Produk Wisata $(+0,1990)$ dan Gaya Hidup $(+0,1187)$.

\section{Evaluasi Model Struktural (Structural Model).}

Tabel 7 menunjukkan bahwa nilai $R$ - Square pada konstruk Keputusan Berkunjung pada Obyek Wisata di Kota Semarang sebesar 0,9462 bermakna bahwa Keputusan Berkunjung pada Obyek Wisata di Kota Semarang dipengaruhi Gaya Hidup, Destination Image dan Atribut Produk Wisata sebesar 94,62\%. Q Square dihitung untuk 
menunjukkan bahwa model memiliki predictive relevance kuat karena nilai yang dihasikan sebesar 0.8953 .

Tabel 7. Nilai $R$ - Square

\begin{tabular}{|l|c|c|}
\hline \multicolumn{1}{|c|}{ Variabel } & $R$ - Square & $\begin{array}{c}Q-\text { Square } \\
\left\{\left(1-\left(1-\mathrm{R}^{2}\right)\right\}\right.\end{array}$ \\
\hline $\begin{array}{l}\text { Y (Keputusan Berkunjung ke Obyek Wisata di } \\
\text { Kota Semarang) }\end{array}$ & 0.9462 & 0.8953 \\
\hline
\end{tabular}

Sumber : data primer yang diolah, 2019

\section{Pembahasan}

Hasil uji Hipotesis menunjukkan bahwa Gaya Hidup terbukti signifikan pada Keputusan Berkunjung pada Obyek Wisata di Kota Semarang $(4,0747>1,96)$. Hal ini dapat dijelaskan bahwa Keputusan Berkunjung pada Obyek Wisata di Kota Semarang disebabkan karena prestige dan status sosialnya, artinya bahwa semakin tinggi status sosial seseorang akan semakin sering berkunjung ke obyek wisata di Kota Semarang. Pengaruh antara Destination Image dengan Keputusan Berkunjung pada Obyek Wisata di Kota Semarang terbukti signifikan dengan nilai $t_{\text {statistik }}$ sebesar 4,3603 (> 1,96). Maknanya bahwa destinasi yang dicitrakan semakin baik akan mempengaruhi Keputusan Berkunjung pada Obyek Wisata di Kota Semarang. Nilai original sample estimate sebesar $+0,3203$, menunjukkan bahwa arah hubungan antara Destination Image dengan Keputusan Berkunjung pada Obyek Wisata di Kota Semarang positif. Maknanya bahwa apabila destinasi dicitrakan semakin baik maka Keputusan Berkunjung pada Obyek Wisata di Kota Semarang semakin meningkat. Atribut Produk Wisata mampu mempengaruhi Keputusan Berkunjung pada Obyek Wisata di Kota Semarang, hal tersebut ditunjukkan dengan nilai $t_{\text {statistik }}$ sebesar 2,3828 $(>1,96)$, artinya bahwa apabila Obyek Wisata di Kota Semarang dilengkapi dengan atribut produk wisata akan mempengaruhi Keputusan Berkunjung pada Obyek Wisata di Kota Semarang.. Nilai original sample estimate sebesar $+0,1990$ bermakna bahwa semakin lengkap atribut produkwisata akan meningkatkan Keputusan Berkunjung pada Obyek Wisata di Kota Semarang.

Hasil uji moderasi ditunjukan bahwa interaksi variabel Electronic Word of Mouth dengan variabel Gaya Hidup ( $\left.{ }^{*} \mathrm{X} 1\right)$ pada variabel Keputusan Berkunjung ke Obyek Wisata di Kota Semarang sebesar 5,0178 lebih besar dari tabel 1,96, sedangkan Koefisien $\mathrm{t}_{\text {statistik }}$ Electronic Word of Mouth dengan Keputusan Berkunjung ke Obyek Wisata di Kota Semarang sebesar 0,36759 lebih kecil dari $t_{\text {tabel }}$ 1,96. Maknanya bahwa interaksi variabel Electronic Word of Mouth dengan variabel Gaya Hidup (M*X1) pada variabel Keputusan Berkunjung ke Obyek Wisata di Kota Semarang signifikan sementara Electronic Word of Mouth dengan Keputusan Berkunjung ke Obyek Wisata di Kota Semarang tidak signifikan. Hal tersebut bermakna bahwa Electronic Word of Mouth mampu berperan sebagai pure moderator, artinya Electronic Word of Mouth memoderatori pengaruh Gaya Hidup dengan Keputusan Berkunjung ke Obyek Wisata di Kota Semarang.

Nilai original sample estimate sebesar +0,2106 menunjukkan bahwa arah Electronic Word of Mouth berperan murni memoderasi pengaruh Gaya Hidup pada Keputusan Berkunjung ke Obyek Wisata di Kota Semarang positip. Pure Moderator 
bermkana bahwa ketika semakin banyak menggunakan media electronik untuk mencari obyek wisata di kota Semarang, akan menguatkan pengaruh Gaya Hidup pada Keputusan Berkunjung ke Obyek Wisata di Kota Semarang.

\section{KESIMPULAN DAN SARAN}

\section{Kesimpulan}

1. Keputusan Berkunjung pada Obyek Wisata di Kota Semarang dapat ditingkatkan melalui Gaya Hidup, Destination Image, dan Atribut Produk Wisata.

2. Electronic Word of Mouth murni mampu memoderatori pengaruh Gaya Hidup pada Keputusan Berkunjung pada Obyek Wisata di Kota Semarang.

3. Model pada penelitian menghasilkan variabel Gaya Hidup, Destination Image, Atribut Produk Wisata signifikan mempengaruhi Keputusan Berkunjung pada Obyek Wisata di Kota Semarang. Electronic Word of Mouth berperan murni sebagai moderator dengan arah positip, artinya Electronic Word of Mouth menguatkan pengaruh Gaya Hidup pada Keputusan Berkunjung pada Obyek Wisata di Kota Semarang.

4. Nilai Q Square pada variabel Keputusan Berkunjung pada Obyek Wisata di Kota Semarang menunjukkan bahwa model memiliki predictive relevance kuat karena nilai yang dihasikan sebesar 0.8953 .

\section{Saran}

Destination Image memiliki nilai original sample estimate yang paling tinggi dibandingkan Gaya Hidup dan Atribut Produk Wisata. Penyedia obyek wisata di Kota Semarang harus selalu menjaga dan memperbaiki destinasi yang ditawarkan agar menghasilkan image baik bagi calon pengunjung obyek wisata maupun bagi pengunjung yang akan melakukan kunjungan ulang obyek wisata di Kota Semarang.

\section{DAFTAR PUSTAKA}

Arif, E., 2019, The Influence of Electronic Word of Mouth (eWOM), Brand Image, and Price on Re-Purchase Intention of Airline Customers, Journal of Applied Management (JAM), Vol. 17(2), p. 24-32.

Asya, H., Kusumawati, A., dan Mawardi,M.K., 2016, Pengaruh Citra Destinasi terhadap Kepuasan Wisatawan serta dampaknya terhadap Loyalitas Wisatawan (Studi pada Wisatawan Nusantara yang Berkunjung ke Kota Batu, Jurnal Administrasi Bisnis, Vol. 38(1), p. 7-12.

Altekar, S and Anil Keskar, 2014, A Study of the Factors Impacting the Buying Decision Process vis-à-vis Specified Consumer Durables in Noida , Journal of General Management Research, Vol. 1(2), p. 111-123

Chevalier, J. dan Mayzlin D., 2006, The effect of word of mouth on sales: Online book reviews, Journal of Marketing Research,Vol. 43(3), p.345-354Asli, D. A., Tasci dan William, C.G, 2007, Destination Image and Its Functional Relationships, Journal of Travel Research, Vol. 45(4), p. 413-425.

Coban, S. 2016, The effects of the image of destination on tourist satisfaction and loyalty: Jurnal Administrasi Bisnis, Vol. 38(1)p. 78-86. 
Friesner, T. (2014). Consumer behavior: Internal influences. Retrieved from: http://www.marketingteacher.com/internal-influences-lifestyle-and-attitude/. [Accessed 7/5/2015].

Goldsmith, R. 2008. Electronic Word-of-Mouth, Ecommerce: Florida. Idea Group Reference Global.

Hennig-Thurau, T., Gwinner, K. P., Walsh, G., dan Gremler, D. D., 2004, Electronic word-of-mouth via consumeropinion platforms: What motivates consumers to articulate themselves on the Internet. Journal of Interactive Marketing, Vol.18(1), p.38-52.

Hossain, M.K. dan Islam. S., 2019, An Analysis of Destination Attributes to Enhance Tourism Competitiveness in Bangladesh, African Journal of Hospitality, Tourism and Leisure, Vol. 8(2), p.81-88.

Jalilvand, R, Esfahani, S.S., dan Samiei, N., 2011, Electronic word-of-mouth: challenges and opportunities, Procedia Computer Science, Vol. 3 (2), p. $42-$ 46.

Joesyiana, K., 2018, pengaruh word of mouth terhadap keputusan pembelian konsumen pada media online shop shopee di pekanbaru, Jurnal Valuta, Vol. 4(1), p. 21-27.

Kim. (2003). Elsevier-lifestyle analysis: A dimension for future-oriented bank research. Journal of Bank Research.

Kavak, B., dan Gumusluoglu, L., 2007, Segmenting food markets-the role of ethnocentrism and lifestyle in understanding purchasing intentions, International Journal of Market Research, Vol.49(1), 71-94.

Jalilvand, Reza, M. dan Samiei, N., 2012, The Effect of Word of Mouth on Inbound Tourists' Decision for Traveling to Islamic Destination (The Case of Isfahan As a Tourist Destination in Iran). Journal of Islamic Marketing, vol.3(1), p.12-21.

Lahindah, B.L., , Merisa dan Siahaan, R.A., 2016, The Influence of Product Innovation and Service Quality to Buying Decision and the Impact to Repeat Buying at Progo Road, The Asian Journal of Technology Management, Vol. 11(2), p. 118-124.

Mohiudin, Z.A, 2018, Effect of Lifestyle on Consumer Decision Making: A Study of Women Consumer of Pakistan, Journal of Accounting, Business and Finance Research, Scientific Publishing Institute, vol. 2(1), p.12-15.

Madafuri,B., 2018, Implication Of Characteristics Of Tourism Products Towards Marketing Strategy, International Journal of Scientific \& Technology Research Vol.7(8), p. 62-71.

Mardhotillah, I., dan Saino, 2013, Pengaruh Kualitas Layanan Terhadap Keputusan Pembelian Konsumen di Baseball Food Court Universitas Negeri Surabaya. Surabaya: Universitas Negeri Surabaya

Mayasari, W.M., dan Budiatmo, A., 2017, Pengaruh Atribut Produk Wisata dan Word of Mouth terhadap Keputusan Berkunjung pada Objek Wisata Taman Margasatwa Semarang, Jurnal Administrasi Bisnis, Vol.6(1), p. 38-46.

Napitupulu, M.G.P., 2015, Pengaruh gaya Hidup, Motivasi, dan Persepsi Konsumen Pria dalam Pengambilan Keputusan Pembelian pada Salon Tiara di Kota Malang, Jurnal Ilmiah Mahasiswa Fakutas Ekonomi dan Bisnis, Universitas Brawijaya, Vol.3(2), p. 17-25. 
Nofiawaty dan Yuliandi, B., 2014, Pengaruh Store Atmosphere Terhadap Keputusan Pembelian Konsumen pada Outlet Nyenyes Palembang, Jurnal Manajemen dan Bisnis Sriwijaya, vol.12(1),p. 56- 73

Nugroho T., Sumarwan, U, dan Kirbrandoko, 2015, factors influencing the purchase decision of organic tofu, Indonesian Journal of Business and Entrepreneurship, Vol. 1(3), p15-24.

Pangestu, S. D. dan Suryoko, S., 2016, Pengaruh Gaya Hidup (Life Style) dan Harga terhadap Keputusan Pembelian (Studi Kasus pada Pelanggan Peacock Coffie Semarang), Jurnal Administrasi Bisnis, Vol. 5(1) hal.15-23.

Qing, P., Lobo, A., dan Chongguang, L., 2012, The impact of lifestyle and ethnocentrism on consumers' purchase intentions of fresh fruit in China, Journal of Consumer Marketing, Vol.29(1), p.43-51.

Ram, K.P. dan Manoj, K.J., 2014, Consumer buying decisions models: A descriptive study, Intermational Journal of Innovation and Applied Studies, vol. 6(3), p. 20-28.

Sugiyono, 2010, Metode Penelitian Pendidikan, Bandung : Alfabeta

Sathish, S. dan Rajamohan, A., 2012, Consumer Behaviour and Life Style Marketing, International Journal of Marketing, Financial Services \& Management Research, Vol.1(10), p.1-8.

Wibowo, A., dan Soedjono, 2014, Pengaruh Kualitas Layanan, Harga dan Lokasi Terhadap Keputusan Pembelian di "D'Stupid Baker" Surabaya, Jurnal Ilmu Riset Manajemen, vol. 3(12), p.21-29.

Widjaja, T B., 2009, Lfestyle Marketing: Paradigma Baru Pemasaran Bisnis Jasa dan Lifestyle, Jakarta: Penerbit PT. Gramedia Pustaka Utama

Yusuf, A., Sulaeman, E., 2014, Pengaruh Atribut Produk Wisata terhadap Place Branding dan Implikasinya terhadap Keputusan Mengunjungi Destinasi Wisata Pantai (Survey Terhadap Wisatawan Nusantara di Kabupaten Karawang), Jurnal Ilmiah Solusi, Vol. 1(1), p.27-36 